\title{
Fluorescent In Situ Hybridization on Isolated Tumor Cell Nuclei: A Sensitive Method for 1p and 19q Deletion Analysis in Paraffin-Embedded Oligodendroglial Tumor Specimens
}

Ellen Gelpi, M.D., Inge M. Ambros, M.D., Peter Birner, M.D., Andrea Luegmayr, Marcus Drlicek, M.D., Ingeborg Fischer, M.D., Reinhold Kleinert, M.D., Hans Maier, M.D., Michael Huemer, M.D., Brigitte Gatterbauer, M.D., Johann Anton, M.D., Karl Rössler, M.D., Herbert Budka, M.D., Peter F. Ambros, Ph.D., Johannes A. Hainfellner, M.D.

Institute of Neurology (EG, PB, IF, HB, JAH), Institute of Pathology (PB), and Department of Neurosurgery (BG, KR), University of Vienna, Vienna; Children's Cancer Research Institute (CCRI), St. Anna Children's Hospital (IMA, AL, PFA), Vienna; Institute of Pathology, LNK Wagner-Jauregg (MD), Linz; Ludwig Boltzmann Institute of Neurooncology, Kaiser Franz Josef Hospital (MD, IF), Vienna; Institute of Pathology, University of Graz (RK), Graz; Institute of Pathology (HM) and Department of Neurosurgery (JA), University of Innsbruck, Innsbruck; and Department of Neurology, Christian Doppler Hospital (MH), Salzburg, Austria

In oligodendroglial neoplasms, losses of chromosomal material at $1 p$ and $19 q$ associate with chemosensitivity and prolonged survival. Thus, 1p/19q testing is increasingly proposed for use in brain tumor diagnosis and prognostic assessment. Fluorescent in situ hybridization (FISH) is a classic technique for investigation of $1 \mathrm{p} / 19 \mathrm{q}$ status in paraffinembedded tissues. A major limitation of this method is truncation of tumor cell nuclei complicating assessment of hybridization results. In our study, we analyzed $1 p$ and $19 q$ status in a series of 79 oligodendroglial neoplasms (49 oligodendrogliomas, 30 oligoastrocytomas, WHO: 57 Grade II, 22 Grade III tumors) and controls (gliotic brain tissue: $n=4$, diffuse low-grade astrocytoma: $n=4$ ) using FISH on isolated whole tumor cell nuclei, prepared as cytospin preparations, thus bypassing the problem of nuclear truncation. For interpretation of FISH results, we used consensus criteria as defined by the SIOP-Europe Neuroblastoma Study Group for analysis of peripheral neuroblastic tumors. FISH

\footnotetext{
Copyright (C) 2003 by The United States and Canadian Academy of Pathology, Inc.

VOL. 16, NO. 7, P. 708, 2003 Printed in the U.S.A

Date of acceptance: April 1, 2003.

This study was supported by the Scientific Funds of the Mayor of Vienna (Project No. 2026) and by CCRI, St. Anna Children's Hospital Vienna, Vienna, Austria.

This study is a cooperative project of the Austrian Neuro-Oncology Network (ANN, www.ann.at).

Authors EG and IMA contributed equally.

Address reprint requests to: Johannes A. Hainfellner, M.D., Institute of Neurology, AKH 4J, POB 48, Währinger Gürtel 18-20, A-1097 Vienna, Austria; fax: 43-1-40400-5511; e-mail: johannes.hainfellner@akh-wien.ac.at.

DOI: 10.1097/01.MP.0000076981.90281.BF
}

yielded interpretable results in $98.7 \%$ for $1 p$ and 92.1\% for 19q. Chromosome $1 p / 19 q$ alterations comprised deletions (1p: 79.5\%, 19q: 80\%) and imbalances (1p: 11.5\%, 19q: 12.9\%). 1p aberrations were more frequent in oligodendroglioma than in oligoastrocytoma $(100 \%$ versus $75.9 \%, P=.001)$. The frequency of $1 p / 19 q$ alterations was not significantly different in WHO Grade II or Grade III tumors or in primary and recurrent tumors. We conclude that FISH on isolated cell nuclei, with application of the SIOP Europe Neuroblastoma consensus criteria, is a sensitive method for detection and interpretation of $1 p$ and $19 q$ aberrations in paraffin-embedded tissue specimens of oligodendroglial neoplasms.

KEY WORDS: Chemosensitivity, Chromosome 1p, Fluorescent in situ hybridization, Oligodendroglioma. Mod Pathol 2003;16(7):708-715

Oligodendroglioma is a morphologically distinct type of diffuse glioma with variable clinical outcome. In contrast to other types of gliomas, oligodendroglioma is associated with generally good response to adjuvant therapy (1-3). Various clinical, radiological and histological features have been suggested as prognostic factors. However, none of these parameters predicts reliably response to adjuvant therapy $(2,4-11)$.

Recently, DNA losses on chromosomes $1 \mathrm{p}$ and $19 q$ have been disclosed as common genetic alterations in oligodendroglial neoplasms and much less frequently in astrocytic neoplasms (12-18). Patients 
with anaplastic oligodendrogliomas harboring a $1 p / 19 q$ deletion were shown to have a more favorable prognosis and significantly better response to chemotherapy as compared with patients with intact $1 p / 19 q$ status $(1,17,19-23)$. In patients with diffuse low-grade gliomas, the $1 p / 19 q$ status predicts prognosis (24) and the predictive value of $1 \mathrm{p} / 19 \mathrm{q}$ status seems more reliable than histology (25).

Therefore, it has been repeatedly suggested to amend conventional histological evaluation of anaplastic oligodendroglioma and diffuse low-grade gliomas with molecular analysis of chromosome arms $1 p$ and $19 q(1,3,9,19-22,24-26)$. As a consequence, $1 \mathrm{p} / 19 \mathrm{q}$ testing is increasingly proposed for use in the diagnostic setting. Various methods are used for $1 \mathrm{p} / 19 \mathrm{q}$ deletion analysis, in particular PCR-based investigations (microsatellite analysis, real-time PCR), comparative genomic hybridization, and fluorescent in situ hybridization (FISH) techniques (12, 14, 24, 27-30). Consensus criteria for assessment and interpretation of analytical results in brain tumors are, however, lacking. In contrast, in peripheral neuroblastic tumors consensus criteria concerning methodology, evaluation of analytical results and data interpretation of diagnostic $1 p$ testing are well established $(31,32)$.

FISH is a classic technique for molecular cytogenetic testing on paraffin-embedded tissues (33). FISH is not limited by age of material and does not require normal autologous or pooled normal reference tissue. Binding of probes can be controlled microscopically. However, one major limitation is nuclear truncation in tissue sections complicating evaluation and interpretation of hybridization results. To circumvent the problem of signal truncation, an improved FISH technique, that is, FISH on isolated whole tumor cell nuclei, has been developed for chromosome $1 \mathrm{p}$ analysis in germ cell tumors. Side-by-side comparison of both methods has proven that FISH on isolated tumor cell nuclei is superior as compared with conventional FISH on tissue sections (32). FISH on isolated tumor cell nuclei has meanwhile replaced conventional FISH on tissue sections not only in germ cell tumors but also in other tumor types, most notably peripheral neuroblastic tumors $(32,34)$. Studies on oligodendroglial neoplasms have continued to use conventional FISH on tissue sections. Therefore, we investigated applicability of FISH on isolated tumor cells on a large series of oligodendroglial neoplasms and assessed FISH results according to consensus criteria for $1 \mathrm{p}$ analysis in peripheral neuroblastic tumors, as defined by the International Society of Pediatric Oncology Europe (E-SIOP) Neuroblastoma Group (31).

\section{MATERIALS AND METHODS}

A total of 89 paraffin-embedded archival tumor specimens diagnosed as low- and high-grade oligodendrogliomas and oligoastrocytomas were collected from the five major Austrian neuropathology/neurooncology units (Vienna, Graz, Innsbruck, Salzburg, and Linz). Age of the material ranged between 2 and 23 years. Control tissues comprised four cases of gliotic brain tissues (neurosurgically resected specimens of temporal lobe/Ammon's horn sclerosis) and 4 cases of diffuse low-grade astrocytoma. Histological slides, $4 \mu \mathrm{m}$ in thickness, were deparaffinized in xylol. Hematoxylin and eosin (HE) staining and immunohistochemistry for glial fibrillary acidic protein (GFAP, polyclonal antibody Z0334; DAKO, Glostrup, Denmark) and epithelial membrane antigen (EMA, monoclonal antibody E 29, DAKO) were performed according to standard protocols (35). Immunolabeling was visualized with the ChemMate kit (DAKO) and diaminobenzidine as chromogene. The tumor specimens were reclassified according to WHO 2000 criteria (36). Accordingly, we categorized those tumors as oligodendrogliomas which displayed uniform oligodendroglial morphology, and we categorized those tumors as oligoastrocytomas that contained distinct components with oligodendroglial and astrocytic differentiation (Fig. 1). We used the antiGFAP immunostaining pattern as support for the distinction of oligodendroglioma versus oligoastrocytoma. We considered a ring-like perinuclear "gliofibrillary" immunostaining pattern as a characteristic oligodendroglial feature, and we considered immunolabeling of a fibrillary tumor matrix as a characteristic feature of an astrocytic component. We used anti-EMA immunostaining for initial screening of the cases to exclude immunoreactive cell surface structures, a feature that would indicate clear cell ependymal neoplasms.

For FISH analysis, we marked representative tumor areas on HE stained sections. Corresponding areas were identified on the paraffin blocks, and core tissue biopsies of $1.5 \mathrm{~mm}$ in diameter were taken from each block using a Yamshidi needle. The same procedure was used for sampling of control tissues. We prepared isolated cell nuclei of tumor and control samples as described previously (32). In detail, the paraffin-embedded tissue samples and 1-mm-diameter glass pellets were put into small bags of nylon gauze. The material was then deparaffinized with xylene for 1.5-3 hours, followed by an ethanol row with decreasing concentrations $(100 \%$, $90 \%, 70 \%$, and $35 \%$ for $1 \mathrm{~h}$, respectively). After transfer into distilled water, the deparaffinized tissue specimens were incubated with $0.1 \%$ protease (Sigma P8038, St. Louis, MO) in $0.1 \mathrm{~N}$ Tris-HCl at $37^{\circ} \mathrm{C}$ for $3-10$ minutes and was agitated occasion- 

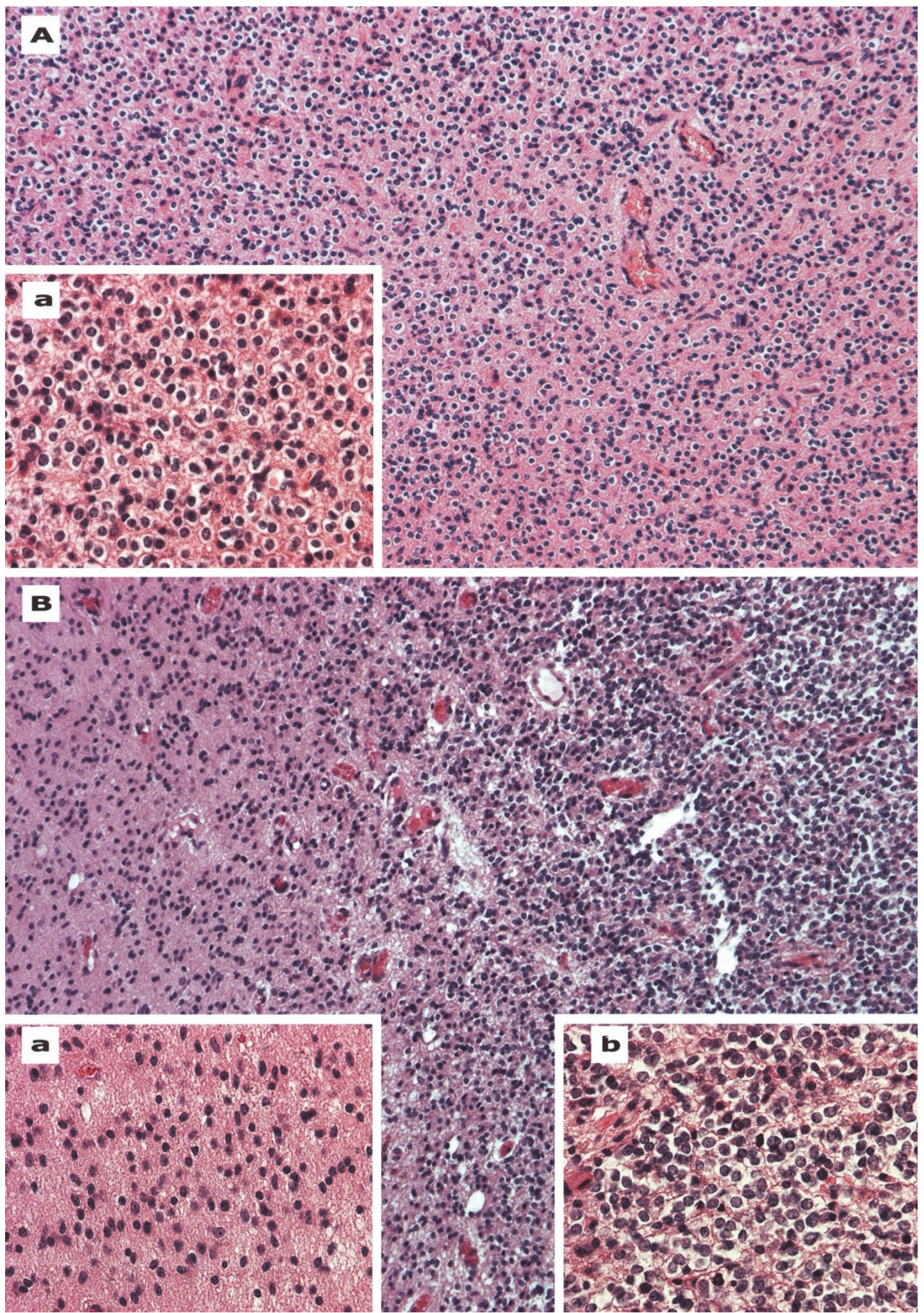

FIGURE 1. Representative histology of oligodendrogliomas and oligoastrocytomas. (A: HE, 100×; inset a: HE; magnification, 170×). Oligodendrogliomas are characterized by a uniform oligodendroglial, that is, clear cell morphology, whereas (B: HE, 100×) oligoastrocytomas are composed of distinct astrocytic (inset $\boldsymbol{a}$ : HE, 170×) and oligodendroglial (inset $\boldsymbol{b}$ : HE, 170×) components.

ally. Afterwards, the digestion was stopped on ice. For checking of digestion, $10 \mu \mathrm{L}$ of 4'-6-diamidino2-phenylindole-2HCl (DAPI; $0.002 \mu \mathrm{L} / \mathrm{mL}$ PBS) and $10 \mu \mathrm{L}$ of cell suspension were put on a slide, cov- ered by coverslip and examined under the fluorescence microscope. Cytospins on glass slides were prepared by centrifugation of $50-100 \mu \mathrm{L}$ cell suspensions $(8 \mathrm{~min}, 500 \mathrm{rpm}$ ) with the help of a 
SHANDON-Cytospin 2 cytocentrifuge (Pittsburgh, PA). The cytospin preparations were air-dried for 2-24 hours and fixed with $4 \%$ buffered formaldehyde for 10 minutes. The samples were immediately processed for FISH or stored before FISH in sealed boxes at $-20^{\circ} \mathrm{C}$ or $-80^{\circ} \mathrm{C}$. $1 \mathrm{p}$ analysis was performed with the paracentromeric probe D1Z1 (1q12) (37) and subtelomeric probe D1Z2 (1p36.3; both Q-BIOgene, Heidelberg, Germany) in a double-color FISH approach as described previously. For $19 \mathrm{q}$ analysis, probes 19 pter and 19q13.3 were used (both Vysis, Bergish-Gladbach, Germany). For visualization, the probes were either directly fluorescence labeled or biotin/digoxigeninlabeled probes were detected with fluorescencelabeled antibodies.

Assessment and interpretation of FISH results were performed according to guidelines defined by the International Society of Pediatric Oncology (ESIOP Neuroblastoma Study Group) for studies of peripheral neuroblastic tumors (31). In each case, hybridization signals of $\geq 200$ tumor cell nuclei were assessed. The ratios between the numbers of paracentromeric and subtelomeric regions of chromosomes $1 \mathrm{p}$ and $19 \mathrm{q}$ were calculated.

Deletion: ratio of paracentromeric and subtelomeric signals $=2 / 1$, partially in conjunction with $4 / 2,3 / 1,4 / 1$ ratios. This hybridization pattern indicates the presence of an $\mathrm{LOH}$.

Imbalance: disproportion of the ratio of paracentromeric and subtelomeric signals, number of subtelomeric signals $>1(=3 / 2,4 / 3,4 / 2,5 / 3$, etc. $)$. Such a result can indicate but does not prove an $\mathrm{LOH}$. Clarification of this specific question requires complementary techniques, such as PCR or Southern blot analysis.

No deletion, no imbalance-normal result: equal ratio of paracentromeric and subtelomeric signals $=2 / 2,4 / 4$.

Unclear result: result is not interpretable because of material (too little tissue, calcifications, etc.) or technical reasons (enzymatic overdigestion).
Statistical testing was performed using $\chi^{2}$ test and $\kappa$ statistic as appropriate. Two-tailed $P$ values $\leq .05$ were considered as statistically significant.

\section{RESULTS}

On histological review, we classified 49 specimens as pure oligodendrogliomas and 30 specimens as oligoastrocytomas. Ten tumors were excluded from further analysis because histology revealed features of clear cell ependymoma in 3 cases, subependymoma in one case, astrocytoma in two cases, primitive neuroectodermal tumor (PNET) in one case, glioblastoma with focal oligodendroglial features in one case, and unclassifiable clear cell gliomas in two cases. The cohort of oligodendroglial neoplasms included 59 primary and 20 recurrent tumors. Fifty-seven specimens fulfilled criteria of Grade II, and 22 cases, Grade III, according to current WHO grading criteria.

We performed 1p analysis in 79/79 tumor cases and $19 q$ analysis in 76/79 tumor cases. In addition, we performed $1 p / 19 q$ analysis in $8 / 8$ controls. FISH showed intact $1 p$ and $19 q$ status (2:2 ratio) in $4 / 4$ gliotic brain tissue samples and in $4 / 4$ diffuse astrocytomas, used as controls. Results in the cohort of oligodendroglial neoplasms are summarized in Table 1. FISH yielded interpretable results in $98.7 \%$ $(78 / 79)$ for $1 p$ and in $92.1 \%(70 / 76)$ for $19 q$. In the remaining cases, results were unclear, because of material (too little tissue, too low tumor cell content in tissue, calcification of the tissue) or methodology (enzymatic overdigestion). In the cohorts with interpretable results (discounting the cases with unclear results), $79.5 \%(62 / 78)$ had $1 p$ deletion and $11.5 \%(9 / 78)$ had $1 p$ imbalance, $80.0 \%(56 / 70)$ had $19 q$ deletion, and $12.9 \%(9 / 70)$ had $19 q$ imbalance. In the total group (including cases with unclear results), 56/76 (73,7\%) had 19q deletion, and 9/76 $(11,8 \%)$ had $19 q$ imbalance. Aberrations in $1 p$ were always present in oligodendrogliomas but not in all oligoastrocytomas (100\% versus $75.9 \%$, exact $\chi^{2}$ test:

TABLE 1. Analysis of $1 p$ and 19q Status in Oligodendrogliomas and Oligoastrocytomas

\begin{tabular}{|c|c|c|c|c|c|c|c|c|c|c|c|c|c|c|}
\hline & \multicolumn{2}{|c|}{ Oligodendroglioma } & \multicolumn{2}{|c|}{ Oligoastrocytoma } & \multicolumn{2}{|c|}{$\begin{array}{l}\text { Primary } \\
\text { Tumors }\end{array}$} & \multicolumn{2}{|c|}{$\begin{array}{c}\text { Recurrent } \\
\text { Tumors }\end{array}$} & \multicolumn{2}{|c|}{$\begin{array}{c}\text { WHO Grade } \\
\text { II }\end{array}$} & \multicolumn{2}{|c|}{$\begin{array}{c}\text { WHO Grade } \\
\text { III }\end{array}$} & \multicolumn{2}{|c|}{ Total } \\
\hline & $\mathrm{n}$ & $\%$ & $\mathrm{n}$ & $\%$ & $\mathrm{n}$ & $\%$ & $\mathrm{n}$ & $\%$ & $\mathrm{n}$ & $\%$ & $\mathrm{n}$ & $\%$ & $\mathrm{n}$ & $\%$ \\
\hline 1p deletion & 42 & 85,7 & 20 & 66,7 & 45 & 76,3 & 17 & 85 & 44 & 77,2 & 18 & 81.9 & 62 & 78,5 \\
\hline 1p imbalance & 7 & 14,3 & 2 & 6,7 & 7 & 11,9 & 2 & 10 & 5 & 8,8 & 4 & 18,1 & 9 & 11,4 \\
\hline 1p normal & 0 & 0 & 7 & 23,3 & 6 & 10,1 & 1 & 5 & 7 & 12,3 & 0 & 0 & 7 & 8,9 \\
\hline \multirow[t]{2}{*}{ 1p unclear } & 0 & 0 & 1 & 3,3 & 1 & 1,7 & 0 & 0 & 1 & 1,2 & 0 & 0 & 1 & 1,2 \\
\hline & 49 & & 30 & & 59 & & 20 & & 57 & & 22 & & 79 & \\
\hline 19q deletion & 37 & 75,7 & 19 & 70,4 & 40 & 71,5 & 16 & 80 & 42 & 77,8 & 14 & 63,6 & 56 & 73,7 \\
\hline 19q imbalance & 6 & 12,2 & 3 & 11,1 & 6 & 10,7 & 3 & 15 & 4 & 7,4 & 5 & 22,7 & 9 & 11,8 \\
\hline $19 q$ normal & 2 & 4,1 & 3 & 11,1 & 5 & 8,9 & 0 & 0 & 4 & 7,4 & 1 & 4,6 & 5 & 6,6 \\
\hline 19q unclear & 4 & 8,2 & 2 & 7,4 & 5 & 8,9 & 1 & 5 & 4 & 7,4 & 2 & 9,1 & 6 & 7,9 \\
\hline \multirow[t]{2}{*}{$19 q$ not done } & 0 & 0 & 3 & - & 3 & - & 0 & - & 3 & - & 0 & - & 3 & - \\
\hline & 49 & & 30 & & 59 & & 20 & & 57 & & 22 & & 79 & \\
\hline
\end{tabular}


$P=.001$ ). Figure 2 shows representative FISH results.

There was a tight positive association of $1 \mathrm{p}$ and $19 q$ alterations (Table 2): $96.9 \%$ (63/65) of the cases with $1 p$ alteration had in addition $19 q$ aberration. Only $5.7 \%(4 / 70)$ had either isolated $1 p$ or $19 q$ aberration. Statistical testing illustrated the high degree of association (kappa: $0.569 ; P<.001$ )
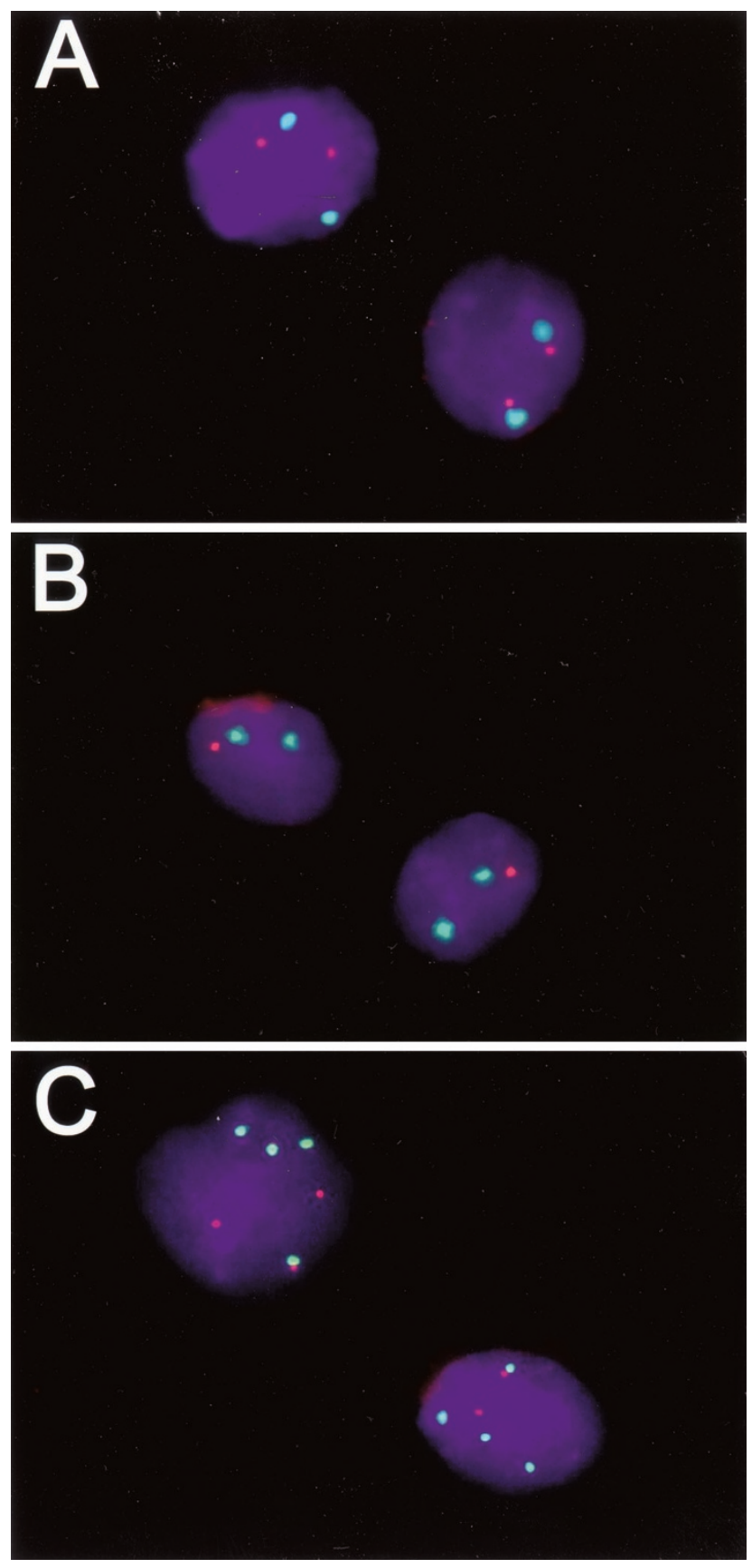

FIGURE 2. FISH analysis of chromosomal arm $1 p$ on isolated cell nuclei. Representative hybridization results are shown in two-cell nuclei (DAPI stain), respectively. A, normal result in a non-neoplastic control case with an equal 2:2 ratio of paracentromeric (green) and subtelomeric (red) signals. B, deletion status in an oligodendroglial neoplasm with a 2:1 ratio of paracentromeric (green) and subtelomeric (red) signals. C, imbalance status in an oligodendroglial neoplasm with 4:2 and 5:3 ratios of paracentromeric (green) and subtelomeric (red) signals. (A-C: original magnification, $3,000 \times$ )
TABLE 2. Combinations of $1 p$ and $19 q$ Status in Oligodendroglial Neoplasms

\begin{tabular}{lccccr}
\hline & $\begin{array}{c}1 \mathrm{p} \\
\text { Deletion }\end{array}$ & $\begin{array}{c}1 \mathrm{p} \\
\text { Imbalance }\end{array}$ & $\begin{array}{c}1 \mathrm{p} \\
\text { Normal }\end{array}$ & $\begin{array}{c}1 \mathrm{p} \\
\text { Unclear }\end{array}$ & \\
\hline 19q deletion & 55 & 0 & 1 & 0 & 56 \\
19q imbalance & 2 & 6 & 1 & 0 & 9 \\
19q normal & 2 & 0 & 3 & 0 & 5 \\
19q unclear & 3 & 3 & 0 & 0 & 6 \\
19q not done & 0 & 0 & 2 & 1 & 3 \\
& 62 & 9 & 7 & 1 & \\
\hline
\end{tabular}

The frequencies of $1 p$ and $19 q$ alterations were not significantly different in primary and recurrent tumors (Table 1): 1p aberrations occurred in $89.7 \%$ $(52 / 58)$ of primary tumors and $95 \%(19 / 20)$ of recurrent tumors $\left(P=.670\right.$; exact $\chi^{2}$ test). 19q aberrations occurred in $90.2 \%$ (46/51) of primary tumors and in $100 \%(19 / 19)$ of recurrent tumors $(P=$ .313). There was also no significant difference in the frequencies of $1 p$ and $19 q$ aberrations in WHO Grade II and Grade III tumors (Table 1): 1p aberrations occurred in $87.5 \%(49 / 56)$ of Grade II tumors and in $100 \%(22 / 22)$ of Grade III tumors $(P=.182)$. $19 q$ alterations occurred in $92 \%(46 / 50)$ of Grade II tumors and in 95\% $(19 / 20)$ of Grade III tumors $(P=$ 1.000).

\section{DISCUSSION}

DNA gains and losses are common alterations in a host of tumors, and some of these DNA alterations correlate with clinical outcome and therapy response (38). In case of primary brain tumors, DNA losses on chromosomes $1 p$ and $19 q$ associate with the oligodendroglial phenotype. Clinicopathological correlation analysis has disclosed that $1 \mathrm{p}$ and $19 q$ aberrations in oligodendroglial neoplasms are predictive for patient survival and chemoresponsiveness $(1,3,7,16,20,22-24,29,39)$. Therefore, determination of the $1 \mathrm{p} / 19 \mathrm{q}$ status is increasingly proposed to be integrated in the diagnostic setting, amending histology (26). Among various techniques, PCR-microsatellite analysis is commonly used for $1 p$ and $19 q$ investigations (28-30). This technique is relatively cheap and fast. However, a major limitation is the need for paired blood samples. In addition, for this kind of studies, the tumor cell content must not be $<60 \%$. Leukocyte preparation in parallel to brain tumor processing and freezing of tumor samples for molecular analysis has not yet become standard in many neuropathology laboratories or is not possible because of lack of dedicated personnel and laboratory space. For $1 \mathrm{p} / 19 \mathrm{q}$ testing, such laboratories have to resort to methods that work on paraffin-embedded brain tumor samples and which do not require paired blood samples. Fulfilling this criterion, FISH is a good method for $1 p / 19 q$ testing on paraffin- 
embedded tissue samples $(22,24,30)$. A further advantage of the FISH technique as compared with PCR is the possibility of investigating tumor tissue at the cellular level. Thus, correlation with morphology and immunocytology, if needed, can be performed. Tumor cell content can be $<60 \%$ (the limit for $\mathrm{LOH}$ studies), and paired blood samples are not needed allowing the use of archival material.

Conventional FISH analysis is performed on histological sections and, therefore, fraught with the problem of nuclear truncation due to cutting of cell nuclei. Assessment of FISH results on sections is a time consuming procedure requiring statistic evaluation of several hundred tumor cell nuclei in each case. For taking nuclear truncation into account, a numerical cutoff of signal ratios has to be defined. In cases with results close to the cutoff value, $1 \mathrm{p}$ and 19q may not be unequivocally classifiable as normal or abnormal. This problem is in particular grave in tumors composed of large tumor cells (e.g., peripheral neuroblastic tumors) with an inherently higher rate of nuclear truncation on histological sections $(32,33,40,41)$. FISH on isolated cell nuclei circumvents the problem of nuclear truncation. In contrast to FISH on histological sections, tumor cell nuclei are isolated mechanically and enzymatically from paraffin-embedded tissue specimens. FISH is then performed on cytospin preparations of the tumor cell nuclei. In case of peripheral neuroblastic tumors, FISH on isolated cell nuclei has proven superior and has replaced conventional FISH on histological sections $(31,32,34)$. To our knowledge, this method has been used so far only in a small series of brain tumors (42). Our study on a large series of oligodendroglial neoplasms shows that FISH on isolated cell nuclei of oligodendroglial neoplasms is a sensitive method for $1 p$ and $19 q$ analysis. Using E-SIOP criteria, the yield of interpretable results is $98.7 \%$ for $1 p$ and $92.1 \%$ for $19 q$.

The majority of our cases with abnormal $1 p / 19 q$ displayed a 2:1 ratio of paracentromeric and subtelomeric FISH signals, definitely indicating an LOH status. However, a portion of tumor specimens showed other abnormal ratios with subtelomeric signals $>1$, for instance, $3: 2$, 4:3, $5: 3$ ratios $(11.5 \%$ for $1 p$ and $12.9 \%$ for $19 q$ ). Such ratios can imply but do not prove an LOH. Therefore, the E-SIOP Neuroblastoma Study Group has designated these ratios as FISH imbalance (31). Previous FISH studies analyzing $1 \mathrm{p} / 19 \mathrm{q}$ status in brain tumors have not discriminated between deletion and imbalance status. It will be important to clarify in future prospective studies the $1 \mathrm{p}$ and $19 \mathrm{q}$ status in oligodendroglial neoplasms with FISH imbalance using FISH and PCR techniques in parallel. Only if FISH imbalance in oligodendroglial neoplasms consistently represents an $\mathrm{LOH}$ status, FISH can be used as sole technique for $1 p / 19 q$ analysis. If FISH imbalance includes oligodendroglial neoplasms with and without a deletion status, PCR analysis will be mandatory as complementary technique, as is the case in peripheral neuroblastic tumors. Clarification of this issue is important for translation of FISH-based $1 \mathrm{p} / 19 \mathrm{q}$ testing on brain tumors into common clinical use.

The majority of our patients received adjuvant radio- and chemotherapy after first operation. These treatments have DNA damaging effects. A possible effect could be the increase of polyploidization of tumor cells and, as a consequence, an increase of the rate of FISH imbalance status (e.g., 4/2 instead of $2 / 1$, or $6 / 2$ instead of $3 / 1$ ). Comparing the frequencies of FISH imbalance in primary and recurrent tumors, we did not detect a significant difference. Thus, tumor recurrency and adjuvant treatment seem not to diminish the diagnostic yield of FISH.

In our cohort of oligodendroglial neoplasms, we found a tight positive association of $1 p$ and $19 q$ aberrations. Only 5.7\% (4/70) showed either isolated $1 p$ or $19 q$ alteration and $96.9 \%(63 / 65)$ of the cases with $1 p$ alteration had in addition $19 q$ alteration. $1 p$ and $19 q$ losses were also tightly associated in other, previously published series of oligodendroglial neoplasms $(12,16,18,20,24,27,30,36,43$, $44)$. On the basis of the $1 p / 19 q$ status, stratification of adjuvant therapy of anaplastic oligodendroglioma has been proposed $(20,26)$. According to this proposal, initial chemotherapy but without radiotherapy should be reserved for patients with combined $1 \mathrm{p} / 19 \mathrm{q}$ losses, whereas patients with isolated $1 p$ loss should be treated with combined chemotherapy and radiotherapy. However, oligodendrogliomas with isolated $1 \mathrm{p}$ loss are rather rare. As survival analysis has been performed so far only in relative small patient cohorts, it has not been proven unequivocally whether there is indeed a significant difference of prognosis and/or response to adjuvant therapy in patients with isolated $1 \mathrm{p}$ loss as compared with patients with combined $1 p / 19 q$ loss. This issue needs to be clarified before stratification of adjuvant treatment on basis of $1 \mathrm{p} / 19 \mathrm{q}$ status can be translated into common clinical use. This will require investigations of large prospective patient cohorts using carefully validated laboratory techniques for $1 \mathrm{p} / 19 \mathrm{q}$ analysis.

\section{REFERENCES}

1. Cairncross JG, Ueki K, Zlatescu MC, Lisle DK, Finkelstein DM, Hammond RR, et al. Specific genetic predictors of chemotherapeutic response and survival in patients with anaplastic oligodendrogliomas. J Natl Cancer Inst 1998;90(19): 1473-9.

2. Giannini C, Scheithauer BW, Weaver AL, Burger PC, Kros JM, Mork S, et al. Oligodendrogliomas: reproducibility and prog- 
nostic value of histologic diagnosis and grading. J Neuropathol Exp Neurol 2001;60(3):248-62.

3. Paleologos NA, Cairncross JG. Treatment of oligodendroglioma: an update. Neurooncol 1999;1(1):61-8.

4. Bauman G, Lote K, Larson D, Stalpers L, Leighton C, Fisher $\mathrm{B}$, et al. Pretreatment factors predict overall survival for patients with low- grade glioma: a recursive partitioning analysis. Int J Radiat Oncol Biol Phys 1999;45(4):923-9.

5. Daumas-Duport C, Tucker ML, Kolles H, Cervera P, Beuvon F, Varlet P, et al. Oligodendrogliomas. Part II: a new grading system based on morphological and imaging criteria. J Neurooncol 1997;34(1):61-78.

6. Daumas-Duport C, Varlet P, Tucker ML, Beuvon F, Cervera P, Chodkiewicz JP. Oligodendrogliomas. Part I: patterns of growth, histological diagnosis, clinical and imaging correlations: a study of 153 cases. J Neurooncol 1997;34(1):37-59.

7. Fortin D, Macdonald DR, Stitt L, Cairncross JG. PCV for oligodendroglial tumors: in search of prognostic factors for response and survival. Can J Neurol Sci 2001;28(3):215-23.

8. Ludwig CL, Smith MT, Godfrey AD, Armbrustmacher VW. A clinicopathological study of 323 patients with oligodendrogliomas. Ann Neurol 1986;19(1):15-21.

9. Perry A. Oligodendroglial neoplasms: current concepts, misconceptions, and folklore. Adv Anat Pathol 2001;8(4):183-99.

10. Rodriguez-Pereira C, Suarez-Penaranda JM, VazquezSalvado M, Sobrido MJ, Abraldes M, Barros F, et al. Value of MIB-1 labelling index (LI) in gliomas and its correlation with other prognostic factors. A clinicopathologic study. J Neurosurg Sci 2000;44(4):203-9; discussion 209-10.

11. Shaw EG, Scheithauer BW, O'Fallon JR, Tazelaar HD, Davis DH. Oligodendrogliomas: the Mayo Clinic experience. J Neurosurg 1992;76(3):428-34.

12. Bigner SH, Matthews MR, Rasheed BK, Wiltshire RN, Friedman HS, Friedman AH, et al. Molecular genetic aspects of oligodendrogliomas including analysis by comparative genomic hybridization. Am J Pathol 1999;155(2):375-86.

13. He J, Mokhtari K, Sanson M, Marie Y, Kujas M, Huguet S, et al. Glioblastomas with an oligodendroglial component: a pathological and molecular study. J Neuropathol Exp Neurol 2001;60(9):863-71.

14. Jeuken JW, Sprenger SH, Boerman RH, von Deimling A, Teepen HL, van Overbeeke JJ, et al. Subtyping of oligoastrocytic tumours by comparative genomic hybridization. J Pathol 2001;194(1):81-7.

15. Kraus JA, Lamszus K, Glesmann N, Beck M, Wolter M, Sabel $\mathrm{M}$, et al. Molecular genetic alterations in glioblastomas with oligodendroglial component. Acta Neuropathol (Berl) 2001; 101(4):311-20.

16. Maintz D, Fiedler K, Koopmann J, Rollbrocker B, Nechev S, Lenartz D, et al. Molecular genetic evidence for subtypes of oligoastrocytomas. J Neuropathol Exp Neurol 1997;56(10): 1098-104.

17. Pohl U, Cairncross JG, Louis DN. Homozygous deletions of the CDKN2C/p18INK4C gene on the short arm of chromosome 1 in anaplastic oligodendrogliomas. Brain Pathol 1999; 9(4):639-43.

18. Reifenberger J, Reifenberger G, Liu L, James CD, Wechsler W, Collins VP. Molecular genetic analysis of oligodendroglial tumors shows preferential allelic deletions on $19 q$ and $1 p$. Am J Pathol 1994;145(5):1175-90.

19. Bauman GS, Cairncross JG. Multidisciplinary management of adult anaplastic oligodendrogliomas and anaplastic mixed oligo-astrocytomas. Semin Radiat Oncol 2001;11(2): 170-80.

20. Ino Y, Betensky RA, Zlatescu MC, Sasaki H, Macdonald DR, Stemmer-Rachamimov AO, et al. Molecular subtypes of anaplastic oligodendroglioma: implications for patient management at diagnosis. Clin Cancer Res 2001;7(4):839-45.
21. Ino Y, Zlatescu MC, Sasaki H, Macdonald DR, StemmerRachamimov AO, Jhung S, et al. Long survival and therapeutic responses in patients with histologically disparate highgrade gliomas demonstrating chromosome $1 \mathrm{p}$ loss. J Neurosurg 2000;92(6):983-90.

22. Jenkins RB, Curran W, Scott CB, Cairncross G. Pilot evaluation of $1 p$ and $19 q$ deletions in anaplastic oligodendrogliomas collected by a national cooperative cancer treatment group. Am J Clin Oncol 2001;24(5):506-8.

23. Nutt CL, Noble M, Chambers AF, Cairncross JG. Differential expression of drug resistance genes and chemosensitivity in glial cell lineages correlate with differential response of oligodendrogliomas and astrocytomas to chemotherapy. Cancer Res 2000;60(17):4812-8.

24. Smith JS, Perry A, Borell TJ, Lee HK, O’Fallon J, Hosek SM, et al. Alterations of chromosome arms $1 \mathrm{p}$ and $19 \mathrm{q}$ as predictors of survival in oligodendrogliomas, astrocytomas, and mixed oligoastrocytomas. J Clin Oncol 2000;18(3):636-45.

25. Sasaki H, Zlatescu MC, Betensky RA, Johnk LB, Cutone AN, Cairncross JG, et al. Histopathological-molecular genetic correlations in referral pathologist-diagnosed low-grade "oligodendroglioma.” J Neuropathol Exp Neurol 2002;61(1):5863.

26. Louis DN, Holland EC, Cairncross JG. Glioma classification: a molecular reappraisal. Am J Pathol 2001;159(3):779-86.

27. Burger PC, Minn AY, Smith JS, Borell TJ, Jedlicka AE, Huntley $\mathrm{BK}$, et al. Losses of chromosomal arms $1 \mathrm{p}$ and 19q in the diagnosis of oligodendroglioma. A study of paraffinembedded sections. Mod Pathol 2001;14(9):842-53.

28. Koreth J, O'Leary JJ, J ODM. Microsatellites and PCR genomic analysis. J Pathol 1996;178(3):239-48.

29. Louis DN, von Deimling A, Seizinger BR. A (CA)n dinucleotide repeat assay for evaluating loss of allelic heterozygosity in small and archival human brain tumor specimens. Am J Pathol 1992;141(4):777-82.

30. Nigro JM, Takahashi MA, Ginzinger DG, Law M, Passe S, Jenkins RB, et al. Detection of $1 \mathrm{p}$ and $19 \mathrm{q}$ loss in oligodendroglioma by quantitative microsatellite analysis, a real-time quantitative polymerase chain reaction assay. Am J Pathol 2001;158(4):1253-62.

31. Ambros PF, Ambros IM. Pathology and biology guidelines for resectable and unresectable neuroblastic tumors and bone marrow examination guidelines. Med Pediatr Oncol 2001;37(6):492-504.

32. Stock C, Ambros IM, Lion T, Haas OA, Zoubek A, Gadner H, et al. Detection of numerical and structural chromosome abnormalities in pediatric germ cell tumors by means of interphase cytogenetics. Genes Chromosomes Cancer 1994; 11(1):40-50.

33. Stock C, Ambros IM, Mann G, Gadner H, Amann G, Ambros PF. Detection of Ip36 deletions in paraffin sections of neuroblastoma tissues. Genes Chromosomes Cancer 1993;6(1): $1-9$.

34. Ambros IM, Bernard J, Boavida M, Bown N, Caron H, Combaret V, et al. Quality assessment of genetic markers used for therapy stratification. J Clin Oncol 2003;21:2077-84.

35. Haberler C, Jarius C, Lang S, Rossler K, Gruber A, Hainfellner JA, et al. Fibrous meningeal tumours with extensive noncalcifying collagenous whorls and glial fibrillary acidic protein expression: the whorling-sclerosing variant of meningioma. Neuropathol Appl Neurobiol 2002;28(1):42-7.

36. Kleihues PCWE. World Health Organization [WHO] classification of tumours of the nervous system. Lyon, France: WHO/IARC; 2000.

37. Cooke HJ, Hindley J. Cloning of human satellite III DNA: different components are on different chromosomes. Nucleic Acids Res 1979;6(10):3177-97.

38. Ejeskar K, Sjoberg RM, Abel F, Kogner P, Ambros PF, Martinsson T. Fine mapping of a tumour suppressor candidate 
gene region in 1p36.2-3, commonly deleted in neuroblastomas and germ cell tumours. Med Pediatr Oncol 2001;36(1): 61-6.

39. Bauman GS, Ino Y, Ueki K, Zlatescu MC, Fisher BJ, Macdonald DR, et al. Allelic loss of chromosome $1 \mathrm{p}$ and radiotherapy plus chemotherapy in patients with oligodendrogliomas. Int J Radiat Oncol Biol Phys 2000;48(3):825-30.

40. Ambros IM, Zellner A, Roald B, Amann G, Ladenstein R, Printz D, et al. Role of ploidy, chromosome 1p, and Schwann cells in the maturation of neuroblastoma. N Engl J Med 1996;334(23):1505-11.

41. Ambros PF, Ambros IM, Kerbl R, Luegmayr A, Rumpler S, Ladenstein $\mathrm{R}$, et al. Intratumoural heterogeneity of $1 \mathrm{p}$ deletions and MYCN amplification in neuroblastomas. Med Pediatr Oncol 2001;36(1):1-4.
42. Hashimoto N, Ichikawa D, Arakawa Y, Date K, Ueda S, Nakagawa Y, et al. Frequent deletions of material from chromosome arm 1p in oligodendroglial tumors revealed by double-target fluorescence in situ hybridization and microsatellite analysis. Genes Chromosomes Cancer 1995;14(4): 295-300.

43. Mueller Wolf HC, Hoffmann A, Lanksch W, Kiwit J, Tonn J, Veelken J, et al. Genetic signature of oligoastrocytomas correlates with tumor location and denotes distinct molecular subsets. Am J Pathol 2002;161:313-9.

44. Zlatescu MC, TehraniYazdi A, Sasaki H, Megyesi JF, Betensky RA, Louis DN, et al. Tumor location and growth pattern correlate with genetic signature in oligodendroglial neoplasms. Cancer Res 2001;61(18):6713-5. 